\title{
Resectable Carcinoma
}

National Cancer Institute

\section{Source}

National Cancer Institute. Resectable Carcinoma. NCI Thesaurus. Code C150604.

Carcinoma that is amenable to surgical resection. 